\title{
NMDA Receptor Phosphorylation at a Site Affected in Schizophrenia Controls Synaptic and Behavioral Plasticity
}

\author{
Bo Li ${ }^{2 \star}$ Nino Devidze, ${ }^{1 \star}$ Denis Barengolts, ${ }^{1}$ Naseem Prostak, ${ }^{3}$ Eleana Sphicas, ${ }^{1}$ Alfonso J. Apicella, ${ }^{2}$ Roberto Malinow, ${ }^{4}$ \\ and Effat S. Emamian ${ }^{1,5}$ \\ ${ }^{1}$ The Rockefeller University, New York, New York 10021, ${ }^{2}$ Cold Spring Harbor Laboratory, Cold Spring Harbor, New York $11724,{ }^{3}$ Cell \& Molecular \\ Technologies, Phillipsburg, New Jersey 08865, ${ }^{4}$ Department of Neuroscience, University of California, San Diego, La Jolla, California 92093-0634, \\ and ${ }^{5}$ Advanced Technologies for Novel Therapeutics (ATNT), LLC., Newark, New Jersey 07103
}

Phosphorylation of the NR1 subunit of NMDA receptors (NMDARs) at serine (S) 897 is markedly reduced in schizophrenia patients. However, the role of NR1 S897 phosphorylation in normal synaptic function and adaptive behaviors are unknown. To address these questions, we generated mice in which the NR1 S897 is replaced with alanine (A). This knock-in mutation causes severe impairment in NMDAR synaptic incorporation and NMDAR-mediated synaptic transmission. Furthermore, the phosphomutant animals have reduced AMPA receptor (AMPAR)-mediated synaptic transmission, decreased AMPAR GluR1 subunit in the synapse, and impaired long-term potentiation. Finally, the mutant mice exhibit behavioral deficits in social interaction and sensorimotor gating. Our results suggest that an impairment in NR1 phosphorylation leads to glutamatergic hypofunction that can contribute to behavioral deficits associated with psychiatric disorders.

\section{Introduction}

The NMDA type of glutamate receptors plays an essential role in the induction of synaptic plasticity (Malinow and Malenka, 2002), which is believed to be the cellular mechanism underlying many forms of adaptive behaviors (Kessels and Malinow, 2009). Malfunctioning of NMDA receptors (NMDARs), however, has been implicated in major psychiatric and neurological disorders, such as schizophrenia and Alzheimer's disease (Lau and Zukin, 2007).

A prominent hypothesis of schizophrenia invokes hypofunction of the NMDAR (Coyle et al., 2003; Coyle and Tsai, 2004). Several lines of evidence support this hypothesis. First, administration of noncompetitive NMDAR antagonists, such as phencyclidine or ketamine, to healthy individuals produces the positive, negative, and cognitive symptoms that mimic schizophrenia, and induces and exacerbates those symptoms in schizophrenia patients (Javitt and Zukin, 1991; Krystal et al., 1994; Malhotra et al., 1997; Adler et al., 1999; Thaker and Carpenter, 2001; Pietraszek, 2003). Second, results from in vivo brain imaging studies suggest that NMDAR function is decreased in the brains of schizophrenia patients (Bressan and Pilowsky, 2000; Millan, 2005; Abbott and Bustillo, 2006; Pilowsky et al., 2006)

Received May 4, 2009; revised July 13, 2009; accepted Aug. 10, 2009.

E.S.E. is a 2004 National Alliance for Research on Schizophrenia and Depression (NARSAD) Young Investigator and a 2007 NARSAD Young Investigator and a Lieber Investigator. This work was supported in part by NARSAD (E.S.E.) and National Institutes of Health Grant R01137MH04159 (R.M.). We thank Dr. Donald Pfaff for his advice on the behavioral assays and for providing access to his behavioral facility. We thank Dr. Gabi Treml for her assistance in designing the targeting vector. We also thank Audrey Greenfield for technical assistance.

${ }^{*}$ B.L. and N.D. contributed equally to this work.

Correspondence should be addressed to Effat S. Emamian, Advanced Technologies for Novel Therapeutics (ATNT), LLC., 211 Warren Street, Newark, NJ 07103. E-mail: emame@atnt-usa.com.

DOI:10.1523/JNEUROSCI.2109-09.2009

Copyright $\odot 2009$ Society for Neuroscience ～0270-6474/09/2911965-08\$15.00/0 (but see Bressan et al., 2005). Third, several studies suggest that enhancing NMDAR function can alleviate schizophrenic symptoms (Matsui et al., 1995; Tsai et al., 1998; Javitt, 2004; Millan, 2005; Coyle, 2006) (but see Tuominen et al., 2005). Last, genetic studies have identified several schizophrenia-linked genes that are either directly or indirectly involved in controlling NMDAR function (Harrison et al., 2003; Harrison and Weinberger, 2005; Ross et al., 2006). Despite the progress in the field, there has been inconsistency regarding the nature of NMDAR changes that occur in schizophrenia (Grimwood et al., 1999; Nudmamud and Reynolds, 2001; Konradi and Heckers, 2003; Eastwood, 2004; Beneyto and Meador-Woodruff, 2008). The exact role of NMDAR dysfunction in the etiology of schizophrenia is also unclear.

The NMDAR is phosphorylated in the cytoplasmic tail of each of its subunits, including NR1 and NR2, and phosphorylation of NMDAR has emerged as an important mechanism regulating its trafficking and function (Chen and Roche, 2007). The NR1 subunit of NMDARs is phosphorylated at serine 897 by protein kinase A (PKA) (Tingley et al., 1997). In the frontal cortex and hippocampus of schizophrenia patients, the phosphorylation level of NR1 at S897 is markedly reduced (Emamian et al., 2004a). The functional significance of NR1 S897 phosphorylation in vivo remains elusive. Whether changes in NR1 phosphorylation play a role in the pathogenesis of schizophrenia or that the decreased phosphorylation itself is a compensatory response to the chronic disease is unknown. The main focus of this study is to examine the physiological and behavioral role of NR1 S897 phosphorylation in vivo to gain insight into the link between the decreased phosphorylation at this site and abnormal behaviors.

\section{Materials and Methods}

Generation and characterization of S897A NR1 phosphomutant mice. To construct the targeting vector, a DNA fragment containing the $\mathrm{C}$ termi- 
nus of NR1 was isolated from the bacterial artificial chromosome library. Using a PCR strategy, the amino acid serine at position 897 was mutated to an alanine. A LoxP-FRT-Neo-FRT cassette was inserted into the intron between exon 18 and exon 19 of NR1, and correct orientation was confirmed by sequencing. Linearized targeting vector was injected into embryonic stem (ES) cells. In the recombinant ES cells, the FRT-NeoFRT cassette was excised using FLP recombinase. Positive ES cell clones were injected into C57BL/6 blastocysts. The resulting chimeras were crossed with C57BL/6 mice. Heterozygous mice were bred to produce homozygotes and wild types (WTs). Successful gene targeting was confirmed by sequencing the genomic DNA from the mutant mice. Using a specific antibody against the phosphorylated NR1 at S897, the deficiency of NR1 S897 phosphorylation in the mutant mice was confirmed by Western blot analysis (described below).

Western blot analysis. Tissues from frontal cortex, striatum, or hippocampus of mouse brain $(0.05-0.1 \mathrm{~g})$ were homogenized in ice-cold lysate buffer $(0.25 \mathrm{M}$ Tris, $\mathrm{pH} 7.5)$ containing protease inhibitors (protease inhibitor mixture tablets; Roche Diagnostics) and phosphatase inhibitors (phosphatase inhibitor mixtures I and II; Sigma-Aldrich) and were lysed through three cycles of freezing (in liquid nitrogen) and thaw (in $37^{\circ} \mathrm{C}$ water bath). Protein concentration was measured (Bio-Rad protein assay) with spectrometry at $595 \mathrm{~nm}$. Equal amounts of total protein were loaded on $4-12 \%$ gradient Bis-Tris gels, separated using the NuPAGE system (Invitrogen) and transferred onto nitrocellulose membrane. The membrane was probed with primary and secondary antibodies, and signals were detected by chemiluminescence followed by autoradiography. The following antibodies were used: anti-NR1 (raised against a conserved sequence of different NR1 splice variants; BD Biosciences Pharmingen and Millipore; 1:1000), anti-GluR1 (Millipore Bioscience Research Reagents; 1:1000), anti-S897 NR1 (Cell Signaling; 1:500; and Millipore; 1:5000), and anti-postsynaptic density 95 (PSD-95) (Millipore; 1:2000).

Immunohistochemistry and electron microscopy. Mice were anesthetized and perfused with $4 \%$ paraformaldehyde, and brain tissues were removed and postfixed overnight. Parasagittal brain sections of $60 \mu \mathrm{m}$ thickness were obtained using a vibratome and were briefly treated with $0.1 \%$ glutaraldehyde. Sections were then washed with $0.1 \mathrm{~m}$ phosphate buffer, $\mathrm{pH} 7.4$, and were blocked overnight with $2 \%$ normal goat serum. Sections were incubated for $48 \mathrm{~h}$ in blocking solution with 1:400 dilution of anti-GluR1 antibody (Millipore Bioscience Research Reagents). Sections were washed four times, $15 \mathrm{~min}$ each, in $0.1 \mathrm{M}$ Tris-saline buffer and incubated with anti-rabbit secondary antibody (included in the ABC kit; Vector Laboratories) for $16 \mathrm{~h}$, and were then washed four times, $15 \mathrm{~min}$ each, in Tris-saline buffer. Using the ABC kit (Vector Laboratories), the brain sections were then subjected to the DAB reaction following the kit instructions. Electron microscopy analysis was performed following the methods of Brown and Farquhar (1989). Sections were postfixed and stained in reduced osmium tetroxide $(1 \% \mathrm{OsO} 4,1 \%$ potassium ferrocyanide, in $0.1 \mathrm{M}$ cacodylate) for $1 \mathrm{~h}$ on ice, and were dehydrated through a graded series of ethanol (50, 70, 95, and 100\%). After this step, samples were treated with $100 \%$ propylene oxide for $30 \mathrm{~min}$ and infiltrated with Epon/propylene oxide (1:1) overnight. Samples were treated with two changes of $100 \%$ Epon, $2 \mathrm{~h}$ each. Sections were then cured on top of precured blocks in a $60^{\circ} \mathrm{C}$ oven for $48 \mathrm{~h}$. Ultrathin sections were cut with a diamond knife on Ultracut-E (Reichart-Jung) and poststained with uranyl acetate and lead. Sections were scanned and pictures were taken on a Tecnai transmission electron microscope (FEI) fitted with Gatan 895 UltraScan digital camera.

Preparation of synaptic-associated proteins. Hippocampi of both brain hemispheres were dissected and homogenized in $0.5 \mathrm{ml}$ of $0.32 \mathrm{M}$ sucrose supplemented with protease and phosphatase inhibitors. Fifty microliters of each sample was stored, and another $1 \mathrm{ml}$ of sucrose was added to the rest of each sample. Samples were centrifuged at $800 \times g$ for $10 \mathrm{~min}$. Supernatants were collected and spun at $10,000 \times g$ for another $10 \mathrm{~min}$. The supernatants were stored, and the pellets were resuspended in a buffer (containing 0.5\% Triton X-100, 120 mm NaCl, 50 mм Tris, pH 7.4, $1 \mathrm{~mm}$ EDTA plus protease and phosphatase inhibitors). Samples were incubated on ice for $30 \mathrm{~min}$ and spun at $21,000 \times g$ for $2 \mathrm{~h}$ to isolate the PSD-95 fraction. Each fractionation experiment was tested by Western blot analysis of equal amount of proteins from each fraction and probing with anti-PSD-95 antibody.

Preparation of acute brain slices. Male, 22- to 25-d-old mice were used for all the electrophysiology experiments. Animals were anesthetized with isoflurane and decapitated, and the brains were quickly removed and chilled in ice-cold dissection buffer ( $110.0 \mathrm{~mm}$ choline chloride, 25.0 $\mathrm{mm} \mathrm{NaHCO}_{3}, 1.25 \mathrm{~mm} \mathrm{NaH}_{2} \mathrm{PO}_{4}, 2.5 \mathrm{~mm} \mathrm{KCl}, 0.5 \mathrm{~mm} \mathrm{CaCl}_{2}, 7.0 \mathrm{~mm}$ $\mathrm{MgCl}_{2}, 25.0 \mathrm{~mm}$ glucose, $11.6 \mathrm{~mm}$ ascorbic acid, $3.1 \mathrm{~mm}$ pyruvic acid; gassed with $95 \% \mathrm{O}_{2} / 5 \% \mathrm{CO}_{2}$ ). Coronal slices $(300 \mu \mathrm{m})$ were cut in dissection buffer using a VT-1000 S vibratome (Leica) and subsequently transferred to a storage chamber containing artificial CSF (ACSF) (118 $\mathrm{mm} \mathrm{NaCl}, 2.5 \mathrm{~mm} \mathrm{KCl}, 26.2 \mathrm{~mm} \mathrm{NaHCO} 3,1 \mathrm{~mm} \mathrm{NaH} \mathrm{PO}_{4}, 20 \mathrm{~mm}$ glucose, $4 \mathrm{mM} \mathrm{MgCl}_{2}, 4 \mathrm{~mm} \mathrm{CaCl}_{2} ; 22-25^{\circ} \mathrm{C}$; $\mathrm{pH}$ 7.4; gassed with $95 \%$ $\mathrm{O}_{2} / 5 \% \mathrm{CO}_{2}$ ). After at least $1 \mathrm{~h}$ of recovery time, slices were transferred to the recording chamber and were constantly perfused with ACSF maintained at $27^{\circ} \mathrm{C}$.

Electrophysiology. Experiments were always performed on interleaved mutant and littermate wild-type animals for comparison. Approximately two-thirds of the experiments were done blind, which showed the same results and were combined with the rest of the data. Whole-cell recordings were obtained with Axopatch-1D amplifiers (Molecular Devices) onto pyramidal neurons in the CA1 region of hippocampus under visual guidance using transmitted light illumination. Synaptic transmission was evoked with a bipolar stimulating electrode placed in the Schaffer collateral pathway, $\sim 0.2 \mathrm{~mm}$ away from cell bodies. Responses were recorded at holding potentials of both $-60 \mathrm{mV}$ (for AMPA receptormediated responses) and $+40 \mathrm{mV}$ (for NMDAR-mediated responses). NMDA receptor-mediated responses were quantified as the mean between 110 and $160 \mathrm{~ms}$ after stimulation. Bathing solution (ACSF) contained the following (in mM): $119 \mathrm{NaCl}, 2.5 \mathrm{KCl}, 4 \mathrm{CaCl}_{2}, 4 \mathrm{MgCl}_{2}, 26.2$ $\mathrm{NaHCO}_{3}, 1 \mathrm{NaH}_{2} \mathrm{PO}_{4}, 11$ glucose, 0.1 picrotoxin, and gassed with $5 \%$ $\mathrm{CO}_{2}$ and $95 \% \mathrm{O}_{2}$ at $27^{\circ} \mathrm{C}$. Internal solution contained the following (in $\mathrm{mM}$ ): 115 cesium methanesulfonate, $20 \mathrm{CsCl}, 10 \mathrm{HEPES}, 2.5 \mathrm{MgCl}_{2}, 4$ $\mathrm{Na}_{2}$-ATP, 0.4 Na-GTP, 10 Na-phosphocreatine, and 0.6 EGTA, pH 7.2. Spontaneous responses [miniature EPSCs (mEPSCs)] were recorded at $27^{\circ} \mathrm{C}$ in the presence of $1 \mu \mathrm{M}$ TTX and $0.1 \mathrm{~mm}$ picrotoxin and analyzed using Mini Analysis Program (Synaptosoft). For recordings on mEPSC or field EPSPs, the concentration for $\mathrm{Ca}^{2+}$ and $\mathrm{Mg}^{2+}$ were adjusted to 2.5 and $1.3 \mathrm{~mm}$, respectively. Electrodes $(\sim 1 \mathrm{~m} \Omega)$ were filled with $1 \mathrm{M}$ $\mathrm{NaCl}$ and placed in the dendritic area $(\sim 0.25 \mathrm{~mm}$ from the somas in CA1) to record field EPSPs. Long-term potentiation (LTP) was induced by stimulating the Schaffer-collateral pathway (two trains of $1 \mathrm{~s}$ pulses at $100 \mathrm{~Hz}$, at an interval of $25 \mathrm{~s}$ ). The result of the LTP experiments was displayed as EPSP amplitude normalized to the average of the responses before LTP induction.

Animals for the behavioral assays. A total of eight male homozygous phosphomutant mice and eight of their wild-type littermates were tested for social interaction, and 10 pairs of homozygous mutants and their wild-type littermates were studied for prepulse inhibition. Adult (6-12 weeks) male cohorts of paired homozygous and their wild-type littermates (with similar body weight) were used for the behavioral assays of this study. Mice were housed individually and were maintained on a $12 \mathrm{~h}$ light/dark cycle with light on at 6:00 P.M. All animals had food and water available ad libitum and were cared for in accordance with the Rockefeller University Institutional Animal Care and Use Committee protocol.

Social interaction. The social interaction paradigm was used as previously described (Choleris et al., 2003). Briefly, a stimulus mouse was presented to an experimental mouse in its home cage, which was covered with a clear Plexiglas top $(23 \times 33 \mathrm{~cm})$. The stimulus mouse was placed in a clear Plexiglas cylinder $(9 \mathrm{~cm}$ in diameter, $10 \mathrm{~cm}$ in height $)$ with 20 holes ( $4 \mathrm{~mm}$ diameter) drilled near the bottom of the cylinder to allow the passage of olfactory cues while preventing direct interaction between the experimental and the stimulus mouse. All tests were done at the dark phase of the light/dark regimen. Before testing, all mice were moved to the darkened testing room with a small red light, and experimental mice were habituated to the presence of an empty cylinder in their home cage for $10 \mathrm{~min}$. Similarly, the stimulus mice were also placed in the clear cylinders and habituated for $5 \mathrm{~min}$ before testing. Each experimental 
A

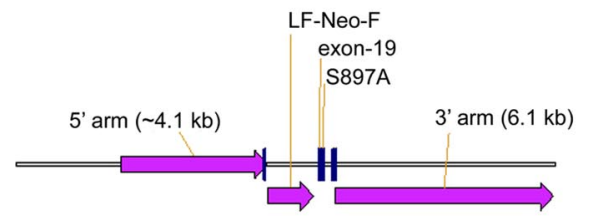

B

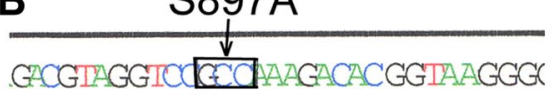

50

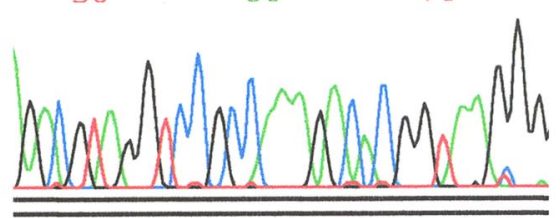

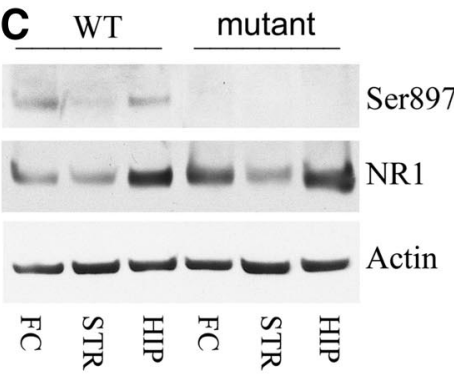

Figure 1. Genetic blockade of NR1 S897 phosphorylation. $A$, Schematic view of the targeting vector generated for targeting the S897 site of GRIN1 locus of the mouse genome (see Materials and Methods). $\boldsymbol{B}$, Confirmation of gene targeting in the genomic DNA of the mutant mice by sequencing using a specific primer close to this site. $\boldsymbol{C}$, Western blot analysis to confirm the absence of phosphorylation at S897 in the S897A mutant animals using the NR1 S897 phosphospecific antibody. Total protein extracts of $50 \mu \mathrm{g}$ from the frontal cortex (FC), striatum (STR), and hippocampus (HIP) of the WT animals and homozygous mutants were loaded. Top blot, Anti-NR1 S897; middle blot, anti-NR1; bottom blot, anti-actin.

mouse was tested five times (tests 1-5) in their home cage, in which a cylinder containing a stimulus mouse was introduced. Each test lasted 5 min, with 15 min intervals in between. In tests $1-4$, the same stimulus mouse was used, whereas in test 5 , a novel stimulus mouse was used. During testing, mice were left undisturbed in the room and their behavior was videotaped ( $8 \mathrm{~mm}$ Canon Handycam) for subsequent analysis. During the $15 \mathrm{~min}$ intertest intervals, the same empty cylinder was placed back in the cage. The position of all the cylinders introduced into the mouse home cage was kept constant throughout the experiment. After every use, cylinders were thoroughly washed with unscented soap and then dried by paper towel. The behavioral data collected include social investigation (active sniffing of the holes) and rearing (not in relation to the cylinder).

Animals' olfactory function was examined to make sure that the deficit in social behavior of the NR1 S897A mutant animals was not caused by changes in the olfactory system. An olfactory stimulus, which was the odor from $100 \%$ benzaldehyde solution (Sigma-Aldrich), was presented for a $20 \mathrm{~s}$ duration when mice were in a "resting state" (i.e., there was no home cage activity detected by the computer [i.e., the total distance (TD) traveled, horizontal activity (HA), and vertical activity (VA) were zero]) for at least $5 \mathrm{~min}$. The changes in the animals' home cage activity (TD, $\mathrm{HA}$, and VA) were measured until the animals reached the resting state again $(\sim 10 \mathrm{~min})$.

Prepulse inhibition of the acoustic startle response. Prepulse inhibition (PPI) of the acoustic startle response was measured as described previously with some minor modifications (Emamian et al., 2004b). Adult homozygous mutant mice and their wild-type littermates were housed individually for 2 weeks before testing. Testing was conducted in a SR-Lab system (San Diego Instruments). Response amplitude was calculated as the maximum response level that occurred during the $100 \mathrm{~ms}$ recording. Because animals can habituate to the prepulse, and to the startle stimulus, the number of trials was kept to minimum. Immediately after being placed in the chamber, the animal was allowed to acclimate for 5 min with background noise $(86 \mathrm{~dB})$ continually present. The animal then received 10 sets of the following five types of trials, distributed pseudorandomly, and separated by 15 s intertrial intervals: trial $1,40 \mathrm{~ms}, 120 \mathrm{~dB}$ noise burst alone; trials $2-4,120 \mathrm{~dB}$ startle stimuli preceded $100 \mathrm{~ms}$ by one of the three $20 \mathrm{~ms}$ prepulses: 90,94 , or $98 \mathrm{~dB}$; trial 5, no-stimulus/ background noise alone $(86 \mathrm{~dB})$. As a control experiment to examine the efficacy of PPI protocol used in this study, wild-type C57BL/6 mice were injected with (+)-5-methyl-10,11-dihydro-5H-dibenzo[a,d]cyclohepten5,10-imine maleate (MK-801) [1 mg/kg; using the methods of Yee et al. (2004)] and subjected to the same PPI protocol described here. This control experiment showed that injection of MK-801 resulted in a significant decrease in PPI (data not shown) using this PPI protocol. Data were analyzed using ANOVA with repeated measures.

\section{Results}

To investigate directly the physiological and behavioral role of NR1 S897 phosphorylation in vivo, we generated a knock-in mouse in which the serine 897 of NR1 is substituted with an alanine (Fig. 1A) (see Materials and Methods), thereby preventing its phosphorylation. We confirmed that the mutant mice carry the point mutation in its genome (Fig. $1 B$ ) and express the full-length NR1 protein at a level comparable with the wild-type mice (Fig. 1C), and the phosphorylation of NR1 at S897 is precluded because of the mutation to alanine (Fig. 1C).

To examine the effects of NR1 S897 phosphomutation on synaptic function, we recorded both NMDAR- and AMPARmediated synaptic transmission in the Schaffer collateral-CA1 synapses in the hippocampi of S897A mutant mice. Compared with wild-type animals, the ratio of NMDAR- to AMPARmediated synaptic transmission was markedly reduced in the mutant animals (Fig. 2A) (WT, $0.82 \pm 0.14, n=10$; mutant mice, $0.31 \pm 0.04, n=12 ; p<0.01)$. The decrease in NMDA-to-AMPA ratio could be attributable to either a decrease of NMDAR- or an increase in AMPAR-mediated synaptic transmission. To distinguish between these possibilities, we recorded AMPAR-mediated mEPSCs from CA1 pyramidal neurons in the hippocampus. We found that both the amplitude (Fig. $2 B$ ) [WT, $13.5 \pm 0.2 \mathrm{pA}, n=$ 1138 events from 10 cells; mutant mice, $12.4 \pm 0.2 \mathrm{pA}, n=662$ events from 10 cells; $p<0.01$ by Kolmogorov-Smirnov (K-S) test] and the frequency (Fig. $2 B$ ) (WT, $13.8 \pm 2.1$ per $\min , n=10$ cells; mutant, $8.5 \pm 1.4$ per min, $n=10$ cells; $p<0.05)$ of the AMPAR-mediated mEPSCs were decreased in the mutant animals. As expected, the interevent intervals of mEPSCs from the mutant animals were longer (Fig. $2 C)(p<0.01$ by K-S test). The reduction of $\mathrm{mEPSC}$ frequency likely reflects a decrease in the number of functional synapses that contain AMPARs, whereas the decrease in mEPSC amplitude is likely attributable to a reduction in the number of AMPARs per synapse. These results demonstrate that both NMDAR- and AMPAR-mediated synaptic transmission onto CA1 cells are reduced. The reduction of NMDA-to-AMPA ratio indicates that the reduction of NMDA transmission is more dramatic than that of AMPA. As expected, given the important role of NMDARs in the induction of LTP, LTP in the Schaffer collateral-CA1 pathway was impaired in the mutant mice (Fig. $2 D)(n=13$ for both WT and mutant animals; $p<0.05)$. These results indicate a severe impairment of NMDAR-mediated synaptic transmission in the mutant animals, leading to decreased synaptic plasticity and AMPAR-mediated synaptic transmission. Since both AMPAR- and NMDARmediated synaptic transmission are markedly impaired, the deficiency of LTP in the mutant animals could be because there is insufficient activation of NMDARs (because of the impairment in AMPAR-mediated synaptic transmission) or insufficient number of NMDARs. 
To determine whether the decreased NMDAR-mediated synaptic transmission is caused by a deficit in NR1 synaptic incorporation in the S897A mutant mice, we prepared synaptic membraneassociated proteins by biochemical fractionation of hippocampal tissue dissected from either the wild-type or the mutant mice. The mutant mice showed a significant decrease in NR1 protein level only in the synaptic fraction (Fig. 3A), whereas NR1 level in the total brain homogenate was unchanged (Fig. 1C, representative blot). Moreover, GluR1 protein level in the synaptic faction (Fig. $3 A$ ), but not in the total homogenate (data not shown), is also significantly reduced in the mutant animals, consistent with the impairment in AMPAR-mediated synaptic transmission (Fig. 2). GluR1-containing AMPAR synaptic insertion requires NMDAR activation (Shi et al., 1999), which underlies LTP in the Schafer collateral-CA1 synapses (Malinow and Malenka, 2002). We therefore also examined the localization of GluR1 in the dendritic spines in the CA1 area of the hippocampus by electron microscopy after immunostaining with a specific antibody against GluR1. Strikingly, unlike the wild-type mice, which showed strong GluR1 immunoreactivity in the PSD region, mutant animals had markedly reduced GluR1 staining near the PSD regions and often formed abnormal clusters within the dendritic spines (Fig. 3B). Quantification of the total number of synapses that positively stained with GluR1 indicates a highly significant decrease in the number of GluR1-positive synapses in the mutant animals $(p<$ 0.0001 by $t$ test) (Fig. $3 B$ ). These data suggest that preventing NR1 S897 phosphorylation caused severe impairment in synaptic NMDAR function such that it is not sufficient to drive effectively GluR1 into the synapse during synaptic plasticity, as evidenced by the reduction in basal synaptic transmission (Fig. 2A-C) and impairment in LTP in the mutant animals (Fig. 2D).

Since the S897A mutation caused severe impairments in glutamatergic synaptic function and plasticity, we wondered whether it could also lead to behavioral deficits. To test this, we examined the mutant mice with behavioral assays commonly used to examine behavioral deficits in rodent models of schizophrenia. We first examined the animal's home cage motor activity and found that, across all the parameters measured (horizontal/vertical activity and total distance traveled), there was no significant difference between the homozygous mutant animals and their wild-type littermates (data not shown), suggesting that the S897A mutation does not affect the overall motor function.

To test whether the phosphomutant animals exhibit deficits in social interaction, we used an assay that examines the social interest in rodents while minimizing the variability that can be introduced by different intruders in a typical social interaction assay based on intruder mice (Choleris et al., 2003). In this assay, each experimental mouse was tested five times (tests $1-5)$ for its
B

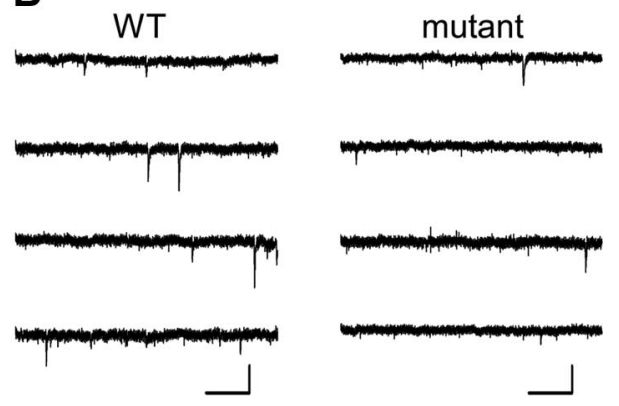

D
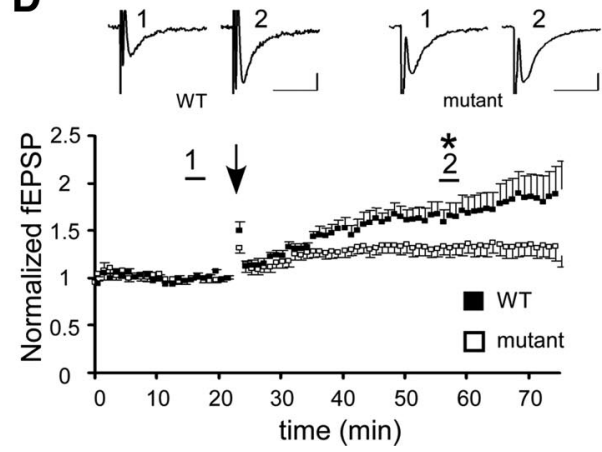

Figure 2. The NR1 S897A mutation depressed synaptic transmission and reduced LTP. $\boldsymbol{A}$, The top panel shows the representative traces of evoked EPSCs recorded from CA1 neurons in either WT or mutant hippocampal slices. EPSCs at both -60 and $+40 \mathrm{mV}$ holding potentials are shown. Calibration: $50 \mathrm{~ms}, 20 \mathrm{pA}$. The bottom histogram is the quantification of the ratio of NMDAR- to 2.* $p<0.01$, K-S test). Quantification of the frequency of AMPAR-mediated mEPSCs for WT and mutant animals is described here ( 2.1 per min, $n=10$ cells; mutant, $8.5 \pm 1.4$ per $\min , n=10$ cells; ${ }^{*} p<0.05, t$ test). $C$, Cumulative distribution of Normalized amplitudes of fEPSPs before and after delivery of the LTP-induction stimuli (arrow). $N=13$ for both WT and mutant animals; ${ }^{*} p<0.05$. Error bars indicate SEM.

reaction to a cylinder containing a stimulus mouse. In tests $1-4$, the same stimulus mouse was used, whereas in test 5 a novel stimulus mouse was introduced. The behavioral data collected included social investigation (active sniffing of the holes near the bottom of the cylinder) and rearing (not in relation to the cylinder). The wild-type mice showed the expected decrease in social response (habituation to the stimulus mouse) throughout tests $1-4$ (comparison between tests 1 vs $4, p<0.001 ; N=8$ ) (Fig. $4 A$ ). The wild-type mice also showed the expected increase in social interest when presented with a novel animal at test 5 (comparison between test 4 vs test $5, p<0.001 ; N=8$ ) (Fig. $4 A$ ). However, the mutant mice did not show the expected decline in the number of social investigations toward the repeatedly introduced stimulus mouse (comparison between tests 1 vs $4, p>$ $0.05 ; N=8$ ) (Fig. $4 A$ ), and also failed to show the expected increase in social investigation toward the novel stimulus mouse (comparison between tests 4 vs $5, p>0.05 ; N=8$ ) (Fig. $4 A$ ). Analysis of the frequency of vertical activity (rearing) showed that the mutant mice exhibited significantly less number of rearing compared with their wild-type littermates in test 1 (Fig. $4 B$ ). However, in tests $2-5$, the difference in vertical activity between mutant and wild-type mice was not significant (Fig. $4 B$ ). The difference in test 1 but not in tests $2-5$ could be attributable to a 
A

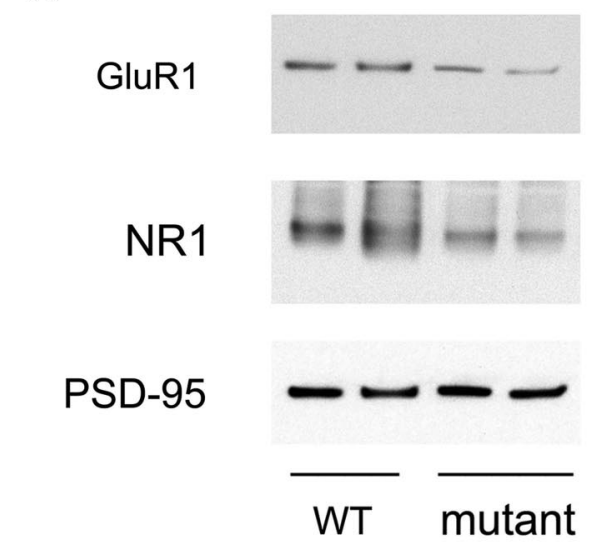

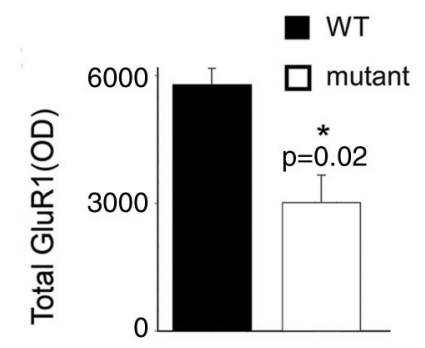

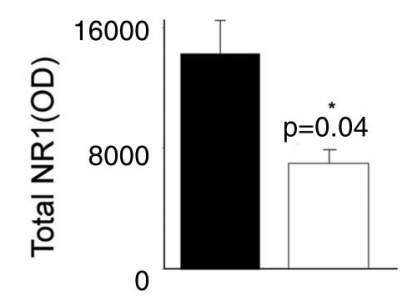

B
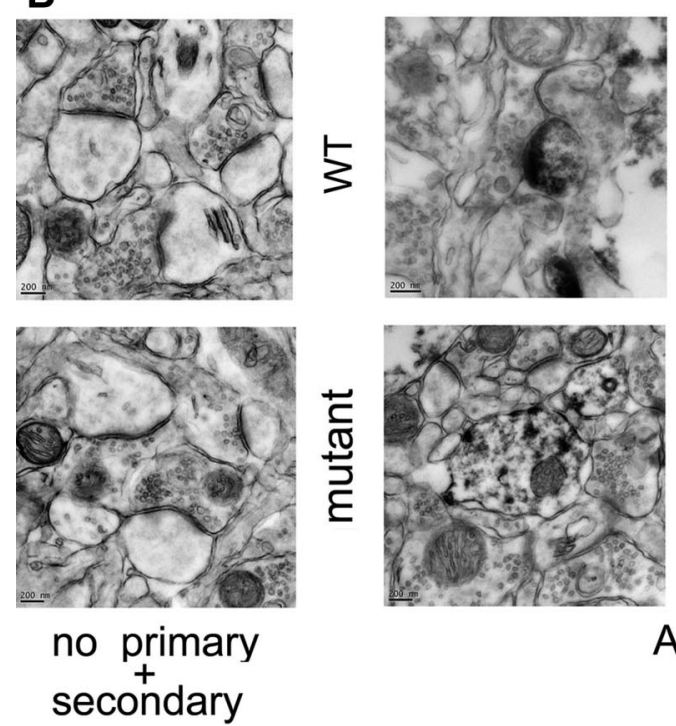
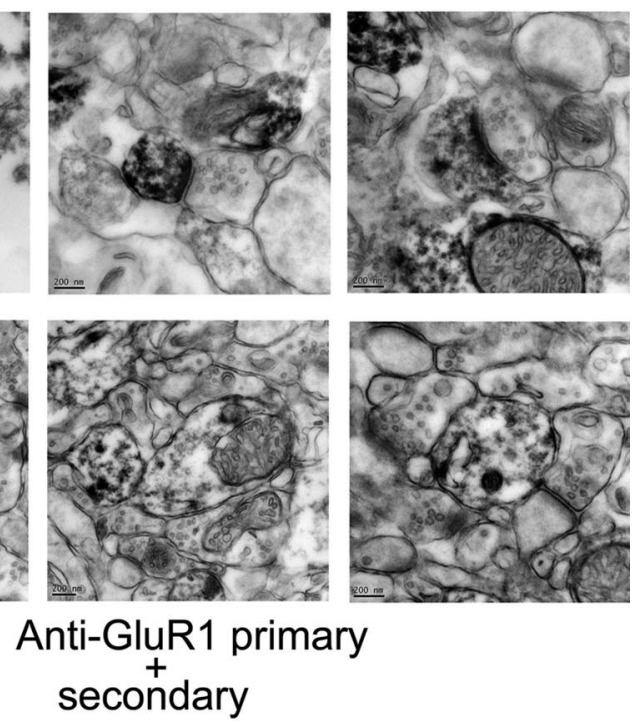

Figure 3. The NR1 S897A mutation decreased synaptic incorporation of glutamate receptors and reduced GluR1 in the synapse. $A$, Left, Western blot analysis after biochemical fractionation of hippocampal tissues dissected from WT and the homozygous mutant mice. Synaptic membrane-associated proteins ( $10 \mu \mathrm{g})$ were loaded, and the same blot was probed with antibodies against GluR1 (top), NR1 (middle), and PSD-95 (bottom). Right, Quantification of the densities of total synaptic GluR1 (top) and NR1 (bottom) signals from WT ( $n=3$ ) and the homozygous mutant ( $n=$ 3) mice. Error bars indicate SEM ( ${ }^{*} p<0.05, t$ test). $\boldsymbol{B}$, Immuno-EM analysis of the CA1 regions of the hippocampus from WT and mutant mice. Left panel, No primary antibody controls; right panels, top, three representative EM fields of the CA1 regions of wild-type animals that were probed with an anti-GluR1 antibody. The dark black staining of GluR1 in postsynaptic areas is the specific GluR1 signal, which is absent in the sections that were probed with the secondary antibody alone (no primary antibody control; on the left). Right panels, Bottom, Three representative EM fields of the CA1 regions of the homozygous mutant mice probed with the anti-GluR1 antibody. The dark black staining shows the mislocalized clusters of GluR1 signal. This signal is specific as it is absent in control sections (probed with the secondary antibody alone; on the left). Quantification of the number of GluR1-positive synapses in each EM field ( $\left.2 \mu \mathrm{m}^{2}\right)$ in the CA1 regions of the wild-type mice and homozygous mutant mice shows a highly significant decrease in the number of GluR1-positive synapses in mutants ( $p<0.0001, t$ test; $N=9$ for both groups). Scale bars, $200 \mathrm{~nm}$.

difference between the wild-type and mutant mice in response to a novel environment. To test whether the deficit in social behavior of the NR1 S897A mutant animals could be explained by a change in olfactory function, we examined the mice for olfactory responsiveness and found that the mutant mice showed normal response to an olfactory stimulus, which was measured as the response to the odor of an $100 \%$ benzaldehyde solution presented when the mice were in resting state (see Materials and Methods) (data not shown). These results demonstrate that the NR1 S897A mutation impairs the function of the brain system that underlies normal social behaviors.

Schizophrenia patients show sensorimotor gating deficits that can be measured as an impairment in PPI, in which a weak auditory prestimulus or prepulse reduces the startle response to a subsequent intense auditory stimulus (Javitt et al., 2008). Abnor- mal PPI has also been used as an indicator of impaired sensorimotor gating in rodent models of schizophrenia (Swerdlow and Geyer, 1998; Geyer et al., 2002). To determine whether the S897A mutation could affect sensorimotor gating, we examined PPI in the phosphomutant animals and their wild-type littermates. We used a combination of one startle stimulus $\left(120 \mathrm{~dB}_{\mathrm{A}}\right)$ preceded by one of the three prepulse stimuli of different intensities $(+4,+8$, and $+12 \mathrm{~dB}_{\mathrm{A}}$ above the background noise). As shown in Figure $4 C$, the phosphomutant animals showed significantly decreased PPI for prepulse intensities of 8 or $12 \mathrm{~dB}_{\mathrm{A}}$ above the background noise (at $+8 \mathrm{~dB}_{\mathrm{A}}, p<0.05, N=10$; at $+12 \mathrm{~dB}_{\mathrm{A}}, p<0.05, N=$ $10)$. We also evaluated the amplitude of the baseline acoustic startle response (in the absence of prepulses). There was no significant difference in the startle response amplitude between the mutant and wild-type animals. These results demonstrate that 

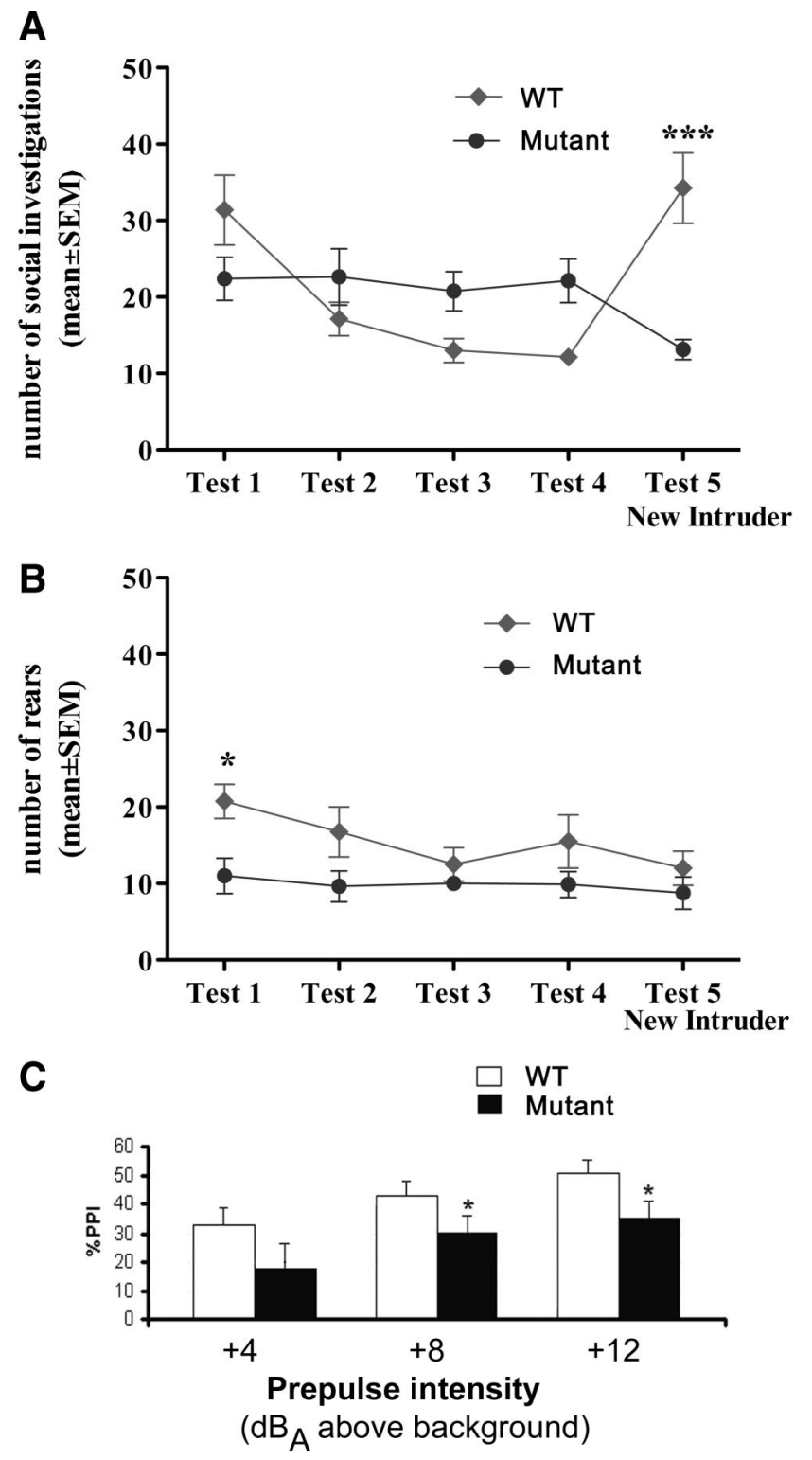

Figure 4. The NR1 S897A mutation causes behavioral deficits. $A, B$, Social interaction of the experimental mice toward the repetitively presented stimulus mouse (tests $1-4$ ), or a novel stimulus mouse (test 5). Mutant, NR1 S897A homozygous mutant mice; WT, wild-type littermates. $A$, Quantification of active social investigation: number of sniffs; $N=8$ for both groups. One-way repeated-measures ANOVA was used to evaluate recognition memory in WT and mutant mice. Significance ( ${ }^{* * *} p<0.0001 ; F=8.3$ ) was further evaluated using Bonferroni's multiple-comparison post hoc test. In test 5 , in which a new intruder was introduced, WT mice showed increased recognition memory compared with mutant mice ( $p<0.001 ; t=5.728$ ). WT mice also showed statistically decreased exploration toward the same intruder through tests $1-4(p<0.01, t=4.226$, test 1 vs test $2 ; p<0.001, t=5.449$, test 1 vs test 3 ; and $p<0.001, t=5.708$, test 1 vs test 4 ), whereas there was no significant difference when compared test 1 (the very first presentation of the intruder, which was presented repeatedly in tests $1-4$ ) with test 5 (the new intruder). In contrary to WT mice, mutant mice did not show recognition memory throughout tests $1-5$. $\boldsymbol{B}$, Quantification of the activity in exploring the cage away from social interest: number of rears (not in relation to the cylinder); $N=8$ for both groups. Compared with mutant mice, WT mice littermate exhibited significantly higher exploratory activity in test $1(p<0.01 ; t=3.4)$. C, Prepulse inhibition of NR1 S897A phosphomutant mice and WT littermate controls. PPI was expressed as $100-[$ (response to startle stimulus after prepulse/response to startle stimulus alone) $\times 100] .{ }^{*} p<0.05 ; N=10$ for both groups. Error bars indicate SEM. the NR1 S897A mutation impairs the plasticity of the startle response (i.e., PPI), while leaving the sensory responsiveness intact, and indicate that NR1 S897 phosphorylation plays a critical role in regulating the function of the neural circuitry underlying sensorimotor gating.

\section{Discussion}

In this study, we found that preventing NR1 S897 phosphorylation in vivo by substituting serine with alanine in mice severely reduces the level and function of NMDARs in the synapse, impairs synaptic plasticity and GluR1 synaptic incorporation, and impairs AMPAR-mediated synaptic transmission. Furthermore, the phosphomutant mice also show deficits in social activities and sensorimotor gating.

Previous studies in cell cultures showed that overexpressed NR1 subunits are retained in the endoplasmic reticulum (ER) because of an ER retention signal near S897 (Standley et al., 2000), and mutations that mimic S897 phosphorylation can suppress the ER retention and facilitate NR1 exiting from ER, thereby regulating the level of NMDARs on cell surface (Xia et al., 2001; Scott et al., 2003). Therefore the impairment in NR1 synaptic incorporation in the phosphomutant animals could be attributable to a failure in phosphorylating NR1 S897 and increased NR1 ER retention. However, ER retention of wild-type NR1 is relieved when it is coexpressed with NR2 subunits (Barria and Malinow, 2002). Since mutant animals express NR1 (Fig. 1C) and NR2 subunits (data not shown) at levels similar to those of wild-type animals, the amount of fully assembled NMDARs that can exit ER in the mutant animals may be comparable with that of wild-type animals. Therefore, the reduction of synaptic NMDARs in the NR1 phosphomutant animals could be attributable to an impairment downstream of ER retention, such as faulty NMDAR synaptic incorporation.

The reduction of AMPA currents and AMPAR synaptic incorporation in the mutant animals could be caused by the primary impairment in NMDAR-mediated synaptic transmission, since NMDARs are essential for both synaptic maturation and plasticity (Constantine-Paton and Cline, 1998). Interestingly, recent studies showed that complete deletion of NR1 (Adesnik et al., 2008; Engblom et al., 2008; Zweifel et al., 2008) or NR2B (Hall et al., 2007) results in potentiation of AMPAR-mediated synaptic transmission. It is possible that low levels of NMDAR function during development act to reduce synaptic AMPAR levels (Sheng and Kim, 2002). The NR1 S897 mutation, which produces low levels of NMDAR function, could enhance this effect. The complete loss of NMDAR function during early development, as achieved by genetic deletion of either NR1 (Adesnik et al., 2008; Engblom et al., 2008; Zweifel et al., 2008) or NR2B (Hall et al., 2007), prevents this normally occurring reduction, leading to a net potentiation of AMPAR transmission. Alternatively, changes in signaling pathways that are normally coupled to NMDAR via NR1 phosphorylation could account for the synaptic depression in the NR1 S897A mutant animals. Additional studies are needed to clarify these issues.

Social behavior and sensorimotor gating are impaired in both schizophrenia patients and rodent models of schizophrenia. In this study, we found that the NR1 S897A mutant mice display significant impairments in social behaviors and sensorimotor gating, as measured by a social interaction paradigm and PPI, respectively. Notably, social abnormalities and PPI deficit similar to those that we observed in the NR1 S897 phosphomutant mice can also be induced in rodents by NMDAR antagonists such as phencyclidine, MK-801, and ketamine (Swerdlow and Geyer, 
1998; Ellenbroek and Cools, 2000; Geyer et al., 2001, 2002; Powell and Miyakawa, 2006). However, neither of the two behavioral phenotypes we observed in the mutant mice is specific to schizophrenia. For example, social interaction deficits can be seen in autism (Moy and Nadler, 2008), and PPI deficits can be seen in other disorders as well (Giakoumaki et al., 2007). Furthermore, it is difficult to draw an analogy between rodent social behaviors, which are primarily driven by olfactory function, with those of humans. Additional studies, including a comprehensive battery of behavioral tests that examine different aspects of cognitive function, are necessary to determine whether this mutation can cause specific cognitive deficits in rodents that are related to schizophrenia or other psychiatric or neurological disorders.

There are several scenarios that can explain how a decrease in NR1 S897 phosphorylation could contribute to abnormal behavior. A decrease in NMDAR function, such as that caused by genetic deficits (Stefansson et al., 2002; Li et al., 2007) or pharmacological treatments (Xu et al., 2006; Mouri et al., 2007; Snyder et al., 2007), may lead to inefficient phosphorylation of NR1 at S897, which further impairs NMDAR function, resulting in a positive-feedback-like mechanism. This will result in impairments in synaptic function and plasticity, and abnormal behaviors. Alternatively, since NR1 S897 is phosphorylated by PKA (Tingley et al., 1997), a primary change in PKA or a phosphatase (such as calcineurin) activity could also lead to changes in S897 phosphorylation. Interestingly, both PKA pathway and calcineurin have been linked to schizophrenia (Sawa and Snyder, 2005; Horiuchi et al., 2007; Kinoshita et al., 2008).

The findings of our study provide new insight for the mechanisms by which NMDAR hypofunction could occur. The NR1 S897A mice therefore can serve as a genetic tool for additional circuit and behavioral analysis.

\section{References}

Abbott C, Bustillo J (2006) What have we learned from proton magnetic resonance spectroscopy about schizophrenia? A critical update. Curr Opin Psychiatry 19:135-139.

Adesnik H, Li G, During MJ, Pleasure SJ, Nicoll RA (2008) NMDA receptors inhibit synapse unsilencing during brain development. Proc Natl Acad Sci U S A 105:5597-5602.

Adler CM, Malhotra AK, Elman I, Goldberg T, Egan M, Pickar D, Breier A (1999) Comparison of ketamine-induced thought disorder in healthy volunteers and thought disorder in schizophrenia. Am J Psychiatry 156:1646-1649.

Barria A, Malinow R (2002) Subunit-specific NMDA receptor trafficking to synapses. Neuron 35:345-353.

Beneyto M, Meador-Woodruff JH (2008) Lamina-specific abnormalities of NMDA receptor-associated postsynaptic protein transcripts in the prefrontal cortex in schizophrenia and bipolar disorder. Neuropsychopharmacology 33:2175-2186.

Bressan RA, Pilowsky LS (2000) Imaging the glutamatergic system in vivorelevance to schizophrenia. Eur J Nucl Med 27:1723-1731.

Bressan RA, Erlandsson K, Stone JM, Mulligan RS, Krystal JH, Ell PJ, Pilowsky LS (2005) Impact of schizophrenia and chronic antipsychotic treatment on [ $\left.{ }^{123} \mathrm{I}\right] \mathrm{CNS}-1261$ binding to $N$-methyl-D-aspartate receptors in vivo. Biol Psychiatry 58:41-46.

Brown WJ, Farquhar MG (1989) Immunoperoxidase methods for the localization of antigens in cultured cells and tissue sections by electron microscopy. Methods Cell Biol 31:553-569.

Chen BS, Roche KW (2007) Regulation of NMDA receptors by phosphorylation. Neuropharmacology 53:362-368.

Choleris E, Gustafsson JA, Korach KS, Muglia LJ, Pfaff DW, Ogawa S (2003) An estrogen-dependent four-gene micronet regulating social recognition: a study with oxytocin and estrogen receptor-alpha and -beta knockout mice. Proc Natl Acad Sci U S A 100:6192-6197.

Constantine-Paton M, Cline HT (1998) LTP and activity-dependent synaptogenesis: the more alike they are, the more different they become. Curr Opin Neurobiol 8:139-148.
Coyle JT (2006) Glutamate and schizophrenia: beyond the dopamine hypothesis. Cell Mol Neurobiol 26:365-384.

Coyle JT, Tsai G (2004) NMDA receptor function, neuroplasticity, and the pathophysiology of schizophrenia. Int Rev Neurobiol 59:491-515.

Coyle JT, Tsai G, Goff D (2003) Converging evidence of NMDA receptor hypofunction in the pathophysiology of schizophrenia. Ann N Y Acad Sci 1003:318-327.

Eastwood SL (2004) The synaptic pathology of schizophrenia: is aberrant neurodevelopment and plasticity to blame? Int Rev Neurobiol 59:47-72.

Ellenbroek BA, Cools AR (2000) Animal models for the negative symptoms of schizophrenia. Behav Pharmacol 11:223-233.

Emamian ES, Karayiorgou M, Gogos JA (2004a) Decreased phosphorylation of NMDA receptor type 1 at serine 897 in brains of patients with schizophrenia. J Neurosci 24:1561-1564.

Emamian ES, Hall D, Birnbaum MJ, Karayiorgou M, Gogos JA (2004b) Convergent evidence for impaired AKT1-GSK3beta signaling in schizophrenia. Nat Genet 36:131-137.

Engblom D, Bilbao A, Sanchis-Segura C, Dahan L, Perreau-Lenz S, Balland B, Parkitna JR, Luján R, Halbout B, Mameli M, Parlato R, Sprengel R, Lüscher C, Schütz G, Spanagel R (2008) Glutamate receptors on dopamine neurons control the persistence of cocaine seeking. Neuron 59:497-508.

Geyer MA, Krebs-Thomson K, Braff DL, Swerdlow NR (2001) Pharmacological studies of prepulse inhibition models of sensorimotor gating deficits in schizophrenia: a decade in review. Psychopharmacology (Berl) 156:117-154.

Geyer MA, McIlwain KL, Paylor R (2002) Mouse genetic models for prepulse inhibition: an early review. Mol Psychiatry 7:1039-1053.

Giakoumaki SG, Roussos P, Rogdaki M, Karli C, Bitsios P, Frangou S (2007) Evidence of disrupted prepulse inhibition in unaffected siblings of bipolar disorder patients. Biol Psychiatry 62:1418-1422.

Grimwood S, Slater P, Deakin JF, Hutson PH (1999) NR2B-containing NMDA receptors are up-regulated in temporal cortex in schizophrenia. Neuroreport 10:461-465.

Hall BJ, Ripley B, Ghosh A (2007) NR2B signaling regulates the development of synaptic AMPA receptor current. J Neurosci 27:13446-13456.

Harrison PJ, Weinberger DR (2005) Schizophrenia genes, gene expression, and neuropathology: on the matter of their convergence. Mol Psychiatry 10:40-68; image 45.

Harrison PJ, Law AJ, Eastwood SL (2003) Glutamate receptors and transporters in the hippocampus in schizophrenia. Ann NY Acad Sci 1003:94-101.

Horiuchi Y, Ishiguro H, Koga M, Inada T, Iwata N, Ozaki N, Ujike H, Muratake T, Someya T, Arinami T (2007) Support for association of the PPP3CC gene with schizophrenia. Mol Psychiatry 12:891-893.

Javitt DC (2004) Glutamate as a therapeutic target in psychiatric disorders. Mol Psychiatry 9:984-997:979.

Javitt DC, Zukin SR (1991) Recent advances in the phencyclidine model of schizophrenia. Am J Psychiatry 148:1301-1308.

Javitt DC, Spencer KM, Thaker GK, Winterer G, Hajós M (2008) Neurophysiological biomarkers for drug development in schizophrenia. Nat Rev Drug Discov 7:68-83.

Kessels HW, Malinow R (2009) Synaptic AMPA receptor plasticity and behavior. Neuron 61:340-350.

Kinoshita Y, Ikeda M, Ujike H, Kitajima T, Yamanouchi Y, Aleksic B, Kishi T, Kawashima K, Ohkouchi T, Ozaki N, Inada T, Harano M, Komiyama T, Hori T, Yamada M, Sekine Y, Iyo M, Sora I, Iwata N (2008) Association study of the calcineurin A gamma subunit gene (PPP3CC) and methamphetamineuse disorder in a Japanese population. Ann N Y Acad Sci 1139:57-62.

Konradi C, Heckers S (2003) Molecular aspects of glutamate dysregulation: implications for schizophrenia and its treatment. Pharmacol Ther 97:153-179.

Krystal JH, Karper LP, Seibyl JP, Freeman GK, Delaney R, Bremner JD, Heninger GR, Bowers MB Jr, Charney DS (1994) Subanesthetic effects of the noncompetitive NMDA antagonist, ketamine, in humans. Psychotomimetic, perceptual, cognitive, and neuroendocrine responses. Arch Gen Psychiatry 51:199-214.

Lau CG, Zukin RS (2007) NMDA receptor trafficking in synaptic plasticity and neuropsychiatric disorders. Nat Rev Neurosci 8:413-426.

Li B, Woo RS, Mei L, Malinow R (2007) The Neuregulin-1 receptor ErbB4 controls glutamatergic synapse maturation and plasticity. Neuron 54:583-597.

Malhotra AK, Pinals DA, Adler CM, Elman I, Clifton A, Pickar D, Breier A 
(1997) Ketamine-induced exacerbation of psychotic symptoms and cognitive impairment in neuroleptic-free schizophrenics. Neuropsychopharmacology 17:141-150.

Malinow R, Malenka RC (2002) AMPA receptor trafficking and synaptic plasticity. Annu Rev Neurosci 25:103-126.

Matsui T, Sekiguchi M, Hashimoto A, Tomita U, Nishikawa T, Wada K (1995) Functional comparison of D-serine and glycine in rodents: the effect on cloned NMDA receptors and the extracellular concentration. J Neurochem 65:454-458.

Millan MJ (2005) N-Methyl-D-aspartate receptors as a target for improved antipsychotic agents: novel insights and clinical perspectives. Psychopharmacology (Berl) 179:30-53.

Mouri A, Noda Y, Noda A, Nakamura T, Tokura T, Yura Y, Nitta A, Furukawa H, Nabeshima T (2007) Involvement of a dysfunctional dopamine-D1/Nmethyl-D-aspartate-NR1 and $\mathrm{Ca}^{2+} /$ calmodulin-dependent protein kinase II pathway in the impairment of latent learning in a model of schizophrenia induced by phencyclidine. Mol Pharmacol 71:1598-1609.

Moy SS, Nadler JJ (2008) Advances in behavioral genetics: mouse models of autism. Mol Psychiatry 13:4-26.

Nudmamud S, Reynolds GP (2001) Increased density of glutamate/Nmethyl-D-aspartate receptors in superior temporal cortex in schizophrenia. Neurosci Lett 304:9-12.

Pietraszek M (2003) Significance of dysfunctional glutamatergic transmission for the development of psychotic symptoms. Pol J Pharmacol 55:133-154.

Pilowsky LS, Bressan RA, Stone JM, Erlandsson K, Mulligan RS, Krystal JH, Ell PJ (2006) First in vivo evidence of an NMDA receptor deficit in medication-free schizophrenic patients. Mol Psychiatry 11:118-119.

Powell CM, Miyakawa T (2006) Schizophrenia-relevant behavioral testing in rodent models: a uniquely human disorder? Biol Psychiatry 59:1198-1207.

Ross CA, Margolis RL, Reading SA, Pletnikov M, Coyle JT (2006) Neurobiology of schizophrenia. Neuron 52:139-153.

Sawa A, Snyder SH (2005) Genetics. Two genes link two distinct psychoses. Science 310:1128-1129.

Scott DB, Blanpied TA, Ehlers MD (2003) Coordinated PKA and PKC phosphorylation suppresses RXR-mediated ER retention and regulates the surface delivery of NMDA receptors. Neuropharmacology 45:755-767.

Sheng M, Kim MJ (2002) Postsynaptic signaling and plasticity mechanisms. Science 298:776-780.

Shi SH, Hayashi Y, Petralia RS, Zaman SH, Wenthold RJ, Svoboda K, Malinow R
(1999) Rapid spine delivery and redistribution of AMPA receptors after synaptic NMDA receptor activation. Science 284:1811-1816.

Snyder GL, Galdi S, Hendrick JP, Hemmings HC Jr (2007) General anesthetics selectively modulate glutamatergic and dopaminergic signaling via site-specific phosphorylation in vivo. Neuropharmacology 53:619-630.

Standley S, Roche KW, McCallum J, Sans N, Wenthold RJ (2000) PDZ domain suppression of an ER retention signal in NMDA receptor NR1 splice variants. Neuron 28:887-898.

Stefansson H, Sigurdsson E, Steinthorsdottir V, Bjornsdottir S, Sigmundsson T, Ghosh S, Brynjolfsson J, Gunnarsdottir S, Ivarsson O, Chou TT, Hjaltason O, Birgisdottir B, Jonsson H, Gudnadottir VG, Gudmundsdottir E, Bjornsson A, Ingvarsson B, Ingason A, Sigfusson S, Hardardottir H, et al. (2002) Neuregulin 1 and susceptibility to schizophrenia. Am J Hum Genet 71:877-892.

Swerdlow NR, Geyer MA (1998) Using an animal model of deficient sensorimotor gating to study the pathophysiology and new treatments of schizophrenia. Schizophr Bull 24:285-301.

Thaker GK, Carpenter WT Jr (2001) Advances in schizophrenia. Nat Med 7:667-671.

Tingley WG, Ehlers MD, Kameyama K, Doherty C, Ptak JB, Riley CT, Huganir RL (1997) Characterization of protein kinase A and protein kinase C phosphorylation of the $N$-methyl-D-aspartate receptor NR1 subunit using phosphorylation site-specific antibodies. J Biol Chem 272:5157-5166.

Tsai G, Yang P, Chung LC, Lange N, Coyle JT (1998) D-Serine added to antipsychotics for the treatment of schizophrenia. Biol Psychiatry 44:1081-1089.

Tuominen HJ, Tiihonen J, Wahlbeck K (2005) Glutamatergic drugs for schizophrenia: a systematic review and meta-analysis. Schizophr Res $72: 225-234$.

Xia H, Hornby ZD, Malenka RC (2001) An ER retention signal explains differences in surface expression of NMDA and AMPA receptor subunits. Neuropharmacology 41:714-723.

Xu DD, Mo ZX, Yung KK, Yang Y, Leung AW (2006) Individual and combined effects of methamphetamine and ketamine on conditioned place preference and NR1 receptor phosphorylation in rats. Neurosignals 15:322-331.

Yee BK, Chang DL, Feldon J (2004) The effects of dizocilpine and phencyclidine on prepulse inhibition of the acoustic startle reflex and on prepulse-elicited reactivity in C57BL6 mice. Neuropsychopharmacology 29:1865-1877.

Zweifel LS, Argilli E, Bonci A, Palmiter RD (2008) Role of NMDA receptors in dopamine neurons for plasticity and addictive behaviors. Neuron 59: $486-496$. 